\title{
A Comparative Research on the Definition of Soft Point
}

\author{
Güzide Şenel \\ Department of Elementary Education, \\ Amasya University, 05100 Amasya, Turkey.
}

\begin{abstract}
The first aim of this study is to compare and contrast definitions of soft point made before. Second is to introduce a new definition of soft point that enables to generate every soft point that changes with each parameter that takes place in a soft set. Third is to compare the definitions with those defined before.
\end{abstract}

\section{General Terms}

2010 AMS Classification: 03G25,20D05, 54A10, 28C15, 54J05, 54A05, $03 \mathrm{HOS}$

\section{Keywords}

Soft set, soft point.

\section{INTRODUCTION}

The soft set theory, initiated by Molodtsov [12], is one of the branches of mathematics, which aims to describe uncertainties. This theory has a rich potential where there is no clearly defined mathematical model, a few of which are indicated by Molodtsov in his pioneer work [12]. In the theory and applications, authors have defined and used different kinds of operations of soft sets. Maji et al. [10, 11] described several applications of soft sets in decision making problems. In [4] authors introduced the soft set relations and related concepts. The soft set theory has been applied to many fields from theoretical to practical [1, 2, 4, 6, 7, 10, 11, 12, 16]. The interesting paper is also [17], where the authors introduced the concept of soft topological spaces and studied separation axioms for topological spaces.

In many aspects of mathematics, soft point theory has a tremendous application such as soft set theoretic operation and the properties of image and pre-image of soft sets under soft mappings. Hence, the concept of point generalized to the theory of soft sets in [3] 18, 21]. Aygünoğlu and Aygün [3] observed that the image of a soft set under constant soft mapping is a soft point as in classical set theory. In [18], a notion of soft point was given and some basic properties of soft point was studied. They introduced a notion of soft metric space which is based on soft point of soft sets. Also, some new concepts in soft topological spaces was introduced in [21] based on the concept of soft point. In 2015, G. Senel [8] introduced the notion of soft matrix of soft points and presented its applications. The main objective of [8] was to observe detailed examination about soft point by soft matrix method which changes with each parameter that takes place in a soft set. The concept of soft point has a very important role in point set topology that involves soft mapping, the image and the inverse of a soft mapping. Until now, to define soft point, the authors have used different subsets of the parameter set for each soft set. This has led not to specify one and each soft set of a soft set's all soft points. The main aim of this paper is comparatively bringing up the difference among the definitions made before and making a valid definition of a soft point.

\section{PRELIMINARY}

In this section, some basic notions of soft set and soft point are recalled which may be found in [3, 6, 7, 11, 12, 18, 21] for further details.

Let $U$ be an initial universe set and let $E$ be a set of parameters. Then, to use an adequate parametrization, Molodtsov [12] made the definition of soft sets as follows;

DEFINITION 1. [12] A pair $(F, E)$ is called a soft set (over $U$ ) if and only if $F$ is a mapping of $E$ into the set of all subsets of the set $U$

Where $F$ is called approximate function and $E$ is called parameters set of the soft set $(F, E)$. For each parameter $x \in E$, the set $F(x)$ is called $x$-approximation of the soft set $(F, E)$ which may be arbitrary, some of them may be empty and some may have a nonempty intersection.

From now on, the soft set $(F, E)$ will be denoted by $F_{E}$.

A soft set $F_{A}$ over $U$ can be written as a set of ordered pairs,

$$
F_{E}=\{(x, F(x)): x \in E\}
$$

Elements of a soft set with empty approximation are normally not listed. Until now, to define the soft sets and their operations, the authors have used different subsets of the parameters set for each soft set. From now on, we will use definitions and operations of soft sets which are more suitable for pure mathematics based on study of $([\overline{6}])$.

DEFINITION 2. ([6]) A soft set $f$ on the universe $U$ is defined by the set of ordered pairs

$$
f=\{(e, f(e)): e \in E\}
$$

where $f: E \rightarrow \mathcal{P}(U)$ such that $f(e)=\emptyset$ if $e \in E \backslash A$ then $f=f_{A}$.

Note that the set of all soft sets over $U$ will be denoted by $\mathbf{S}$.

DEFINITION 3. ([3]) The soft set $F_{A}$ is called a soft point if there exists a $x_{0} \in X$ and $A \subseteq E$ such that $F_{A}(e)=x_{0}$, for all 
$e \in A$ and $F_{A}(e)=\emptyset$, for all $e \in E \backslash A$. A soft point is denoted by $F^{x_{0}} A$.

Definition 4. ([18]) A soft set $(P, A)$ over $X$ is said to be a soft point if there is exactly one $\lambda \in A$, such that $P(\lambda)=\{x\}$ for some $x \in X$ and $P(\mu)=\emptyset, \forall \mu \in A \backslash\{\lambda\}$. It will be denoted by $P^{x}{ }_{\lambda}$.

DEFINITION 5. ([21]) The soft set $(F, A) \in S S(U)$ is called a soft point in $U_{A}$, denoted by $e_{F}$, if for the element $e \in A, F(e) \neq$ $\emptyset$ and $F\left(e^{\prime}\right)=\emptyset$ for all $e^{\prime} \in A \backslash\{e\}$.

\section{DEFINITION OF SOFT POINT}

In this section, contributions to the definition of soft point are given in which will be used two indexed parameters. We know that more than one soft point can be generated with a parameter $e$ and $f$ soft set's all soft points has to specify one and each soft set. The innovation about soft point in this section is, soft point's definition is reformulated with two indexed parameters that must have a response of one and only one in the initial universe.

DEFINITION 6. ([3]) The soft set $f$ is called a soft point in $\boldsymbol{S}$, if for the parameter $e_{i} \in E$ such that $f\left(e_{i}\right) \neq \emptyset$ and $f\left(e_{j}\right)=\emptyset$, for all $e_{j} \in E \backslash\left\{e_{i}\right\}$ is denoted by $\left(e_{i_{f}}\right)_{j}$ for all $i, j \in N^{+}$.

Note that the set of all soft points of $f$ will be denoted by $S P(f)$.

EXAMPLE 1. Let $U=\left\{u_{1}, u_{2}, u_{3}, u_{4}, u_{5}\right\}$ and $E=$ $\left\{e_{1}, e_{2}, e_{3}\right\} . f \in \boldsymbol{S}$ and

$$
f=\left\{\left(e_{1},\left\{u_{1}, u_{2}\right\}\right),\left(e_{2},\left\{u_{2}, u_{3}\right\}\right),\left(e_{3},\left\{u_{1}, u_{2}, u_{5}\right\}\right)\right\}
$$

Then the soft points for the parameter $e_{1}$ are;

$$
\begin{aligned}
& \left(e_{1_{f}}\right)_{1}=\left(e_{1},\left\{u_{1}\right\}\right) \\
& \left(e_{1_{f}}\right)_{2}=\left(e_{1},\left\{u_{2}\right\}\right) \\
& \left(e_{1_{f}}\right)_{3}=\left(e_{1},\left\{u_{1}, u_{2}\right\}\right)
\end{aligned}
$$

one of them can be chosen as soft point.

For the the parameter $e_{2}$ one of three occasions can be chosen as soft point likewise;

$$
\begin{aligned}
& \left(e_{2_{f}}\right)_{1}=\left(e_{2},\left\{u_{2}\right\}\right) \\
& \left(e_{2_{f}}\right)_{2}=\left(e_{2},\left\{u_{3}\right\}\right) \\
& \left(e_{2_{f}}\right)_{3}=\left(e_{2},\left\{u_{2}, u_{3}\right\}\right)
\end{aligned}
$$

The soft points for the parameter $e_{3}$ are;

$$
\begin{aligned}
& \left(e_{3_{f}}\right)_{1}=\left(e_{3},\left\{u_{1}\right\}\right) \\
& \left(e_{3_{f}}\right)_{2}=\left(e_{3},\left\{u_{2}\right\}\right) \\
& \left(e_{3_{f}}\right)_{3}=\left(e_{3},\left\{u_{5}\right\}\right) \\
& \left(e_{3_{f}}\right)_{4}=\left(e_{3},\left\{u_{1}, u_{2}\right\}\right) \\
& \left(e_{3_{f}}\right)_{5}=\left(e_{3},\left\{u_{1}, u_{5}\right\}\right) \\
& \left(e_{3_{f}}\right)_{6}=\left(e_{3},\left\{u_{2}, u_{5}\right\}\right) \\
& \left(e_{3_{f}}\right)_{7}=\left(e_{3},\left\{u_{1}, u_{2}, u_{5}\right\}\right)
\end{aligned}
$$

DEFINITION 7. Let $f \in \boldsymbol{S}$. Then,

If $f(e)=\emptyset$ for all $e \in E$, then $f$ is called null soft point, denoted by $e_{\Phi}$.

If $f(e)=U$ for all $e \in E$, then $f$ is called universal soft point, denoted by $e_{\tilde{E}}$.

If there is only one parameter $e \in E$ in $f$, then $f$ is denoted by $e_{f_{i}}$. If there is only one parameter $e \in E$ in $f$, and $f(e)=\{u\}$ then $f$ is denoted by $e_{f}$.
DEFINITION 8. ([21]) The soft point $\left(e_{i_{f}}\right)_{j}$ is said to belong to a soft set $g \in S$, denoted by $\left(e_{i_{f}}\right)_{j} \tilde{\in} g$, if for the parameter $e_{i} \in E$ and $f\left(e_{i}\right) \subseteq g\left(e_{i}\right)$.

THEOREM 9. ([21]) Let $E$ and $U$ be finite sets. All the soft points of soft set $f$ is equal to

$$
\sum_{e \in E}\left(2^{|f(e)|}-1\right)
$$

where $|f(e)|$ is cardinality of $f\left(e_{i}\right)$.

DEFINITION 10. (21]) The soft points $\left(e_{i_{f}}\right)_{j}$ and $\left(e_{k_{f}}\right)_{s}$ are said to be equal if $e_{i}=e_{k}$ and $f\left(e_{i}\right)=f\left(e_{k}\right)$.

PROPOSITION 1. It is clearly from the definition of soft point that if $e_{i} \neq e_{k}$ then, $\left(e_{i_{f}}\right)_{j} \neq\left(e_{k_{f}}\right)_{s}$. But being $\left(e_{i_{f}}\right)_{j} \neq\left(e_{k_{f}}\right)_{s}$ is not implies to be $e_{i} \neq e_{k}$ as seen in the following example:

EXAMPLE 2. Consider the soft set $f$ is defined in Example 1 . soft points $\left(e_{1_{f}}\right)_{1}=\left(e_{1},\left\{u_{1}\right\}\right)$ and $\left(e_{1_{f}}\right)_{2}=\left(e_{1},\left\{u_{2}\right\}\right)$ are written by the parameter $e_{1}$ but they are different.

Proposition 2. ([[18]) The union of any collection of soft points can be considered as a soft set and every soft set can be expressed as union of all soft points belonging to it. It can be shown as,

$$
f=\tilde{U}\left(e_{i_{f}}\right)_{j} \tilde{\epsilon} f\left(e_{i_{f}}\right)_{j}
$$

EXAMPLE 3. Let $U=\left\{u_{1}, u_{2}, u_{3}\right\}$ and $E=\left\{e_{1}, e_{2}, e_{3}\right\}$. $f \in \boldsymbol{S}$ and

$$
f=\left\{\left(e_{1},\left\{u_{3}\right\}\right),\left(e_{2},\left\{u_{1}, u_{2}, u_{3}\right\}\right)\right\}
$$

All the soft points of $f$ are;

$$
\begin{aligned}
& \left(e_{1_{f}}\right)_{1}=\left(e_{1},\left\{u_{3}\right\}\right) \\
& \left(e_{2_{f}}\right)_{1}=\left(e_{2},\left\{u_{1}\right\}\right) \\
& \left(e_{2_{f}}\right)_{2}=\left(e_{2},\left\{u_{2}\right\}\right) \\
& \left(e_{2_{f}}\right)_{3}=\left(e_{2},\left\{u_{3}\right\}\right) \\
& \left(e_{2_{f}}\right)_{4}=\left(e_{2},\left\{u_{1}, u_{2}\right\}\right) \\
& \left(e_{2_{f}}\right)_{5}=\left(e_{2},\left\{u_{1}, u_{3}\right\}\right) \\
& \left(e_{2_{f}}\right)_{6}=\left(e_{2},\left\{u_{2}, u_{3}\right\}\right) \\
& \left(e_{2_{f}}\right)_{7}=\left(e_{2},\left\{u_{1}, u_{2}, u_{3}\right\}\right)
\end{aligned}
$$

Here we get

$$
f=\sim^{2}\left(\sim^{7} 7=1\left(\left\{e_{i_{f}}\right\}\right)_{j}\right)
$$

From proposition 2 and definitions of soft set and soft point we have the following result:

A soft set can be written as the soft union of all its soft points and every soft point is a soft set.

Proposition 3. ([21]) Let $f, g \tilde{\in} \boldsymbol{S}$. Then,

1. $f \widetilde{\subseteq} g$, if $\left(e_{i_{f}}\right)_{j} \tilde{\in} f$ then $\left(e_{i_{f}}\right)_{j} \tilde{\in} g$ for all $e_{i} \tilde{\in} f$.

2. $f=g$, if and only if $\left(e_{i_{f}}\right)_{j} \tilde{\in} f$ then $\left(e_{i_{f}}\right)_{j} \tilde{\in} g$ and $\left(e_{i_{f}}\right)_{j} \tilde{\in} g$ and $\left(e_{i_{f}}\right)_{j} \tilde{\in} f$ for all $e_{i} \tilde{\in} f$. 


\section{COMPARISON OF THE DEFINITIONS}

In this section, we compare our definition with the definitions given by Sujoy Das et al. [18] and I. Zorlutuna et al. [21]. In [3], the definition of soft point is similar to the definition given by Sujoy Das et al. [18] made in 2013. So, we don't compare it.

Let us first compare the definitions of soft points in Table 1 that takes place in the end of the paper. Definitions 4 and 5 which have not an adequate explanation about soft point. For two different soft points $\left(e_{1_{f}}\right)_{1}$ and $\left(e_{1_{f}}\right)$, in soft set $\mathrm{f}$ have own parameter sets which may be different. It means that there are more than one parameter set where the definitions can be given with different subsets of parameter set.

Let us explain the differences by an example:

EXAMPLE 4. Consider the soft set $f$ is defined in Example 1 . soft points $\left(e_{1_{f}}\right)_{1}=\left(e_{1},\left\{u_{1}\right\}\right),\left(e_{1_{f}}\right)_{2}=\left(e_{1},\left\{u_{2}\right\}\right)$ and $\left(e_{1_{f}}\right)_{2}=\left(e_{1},\left\{u_{1}, u_{2}\right\}\right)$ are written by the parameter $e_{1}$. If we want to write these soft points by [21]'s definition;

$$
\begin{aligned}
& \quad(F, A)=\left\{\left(e_{1},\left\{u_{1}, u_{2}\right\}\right),\left(e_{2},\left\{u_{2}, u_{3}\right\}\right),\left(e_{3},\left\{u_{1}, u_{2}, u_{5}\right\}\right)\right\} \\
& e_{1_{F}}=\left(e_{1},\left\{u_{1}\right\}\right), F\left(e_{1}\right) \neq \emptyset \text { and } F\left(e_{2}\right)=F\left(e_{3}\right)=\emptyset \text {. So, it is } \\
& \text { a soft point. } \\
& e_{1_{F}}=\left(e_{1},\left\{u_{2}\right\}\right), F\left(e_{1}\right) \neq \emptyset \text { and } F\left(e_{2}\right)=F\left(e_{3}\right)=\emptyset \text {. So, it is } \\
& \text { a soft point. }
\end{aligned}
$$

Here, we have to use the same notation $e_{1_{F}}$ for the different soft points. This has led not to specify one and each soft set of a soft set's all soft points.

If we want to write these soft points by [18]'s definition;

$$
\begin{gathered}
(P, A)=\left\{\left(e_{1},\left\{u_{1}, u_{2}\right\}\right),\left(e_{2},\left\{u_{2}, u_{3}\right\}\right),\left(e_{3},\left\{u_{1}, u_{2}, u_{5}\right\}\right)\right\} \\
P^{u_{1}} e_{1}=\left(e_{1},\left\{u_{1}\right\}\right), P\left(e_{1}\right)=\left\{u_{1}\right\} \text { and } P\left(e_{2}\right)=P\left(e_{3}\right)=\emptyset .
\end{gathered}
$$$$
\text { So, it is a soft point. }
$$

From the definition of soft set, $P\left(e_{1}\right)=\left\{u_{1}, u_{2}\right\}$. Here the soft set notation $P$ is used for the soft point notation. On the other hand, if we want to use the soft point $\left(e_{1},\left\{u_{1}, u_{2}\right\}\right)$, will we use the notation $P^{u_{1}, u_{2}} e_{1}=$ ?

In this case, what can we say about different soft points $\left(e_{2_{f}}\right)_{1}=$ ?, $\left(e_{2_{f}}\right)_{2}=$ ? and $\left(e_{3_{f}}\right)_{1}=$ ? How can we show them and make soft point operations?

This cause contributions about definition of soft point.

\section{CONCLUSION}

The main objective of this paper is to observe detailed examination about soft point that becomes significant in point set topology. Firstly, definitions of soft point made before have been given and been compared. Secondly, a reorganised definition of soft point with two sets of parameters that changes with each parameter has been represented. This approach has led to specify one and each soft point. In the sequel, the definitions of soft point have been compared. The definitions made before makes soft set properties and operations contradictory has been demonstrated. This new study is comparatively bringing up the difference among the definitions made before and making a valid definition of a soft point. Based on this new definition, some further work can be done on the properties of each parameter, which may be useful to characterize some other soft mathematical concepts and structures.

\section{REFERENCES}

[1] H. Aktas and N. Cağman, Soft sets and soft groups, Inform. Sci. 177 (2007), 2726-2735.

[2] M. I. Ali, A note on soft sets, Rough soft sets and fuzzy soft sets, Applied Soft Computing, 11 (4) (2011) 3329-3332.

[3] A. Aygŭnoğlu, H. Aygŭn, Some notes on soft topological spaces, Neural Comp. Appl. (2011), 521-011-0722-3.

[4] K.V. Babitha and J.J. Sunil, Soft set relations and functions, Comput. Math. Appl., 607 (2010), no. 7, 1840-1849.

[5] N. Căğman and S. Enginoğlu, Soft set theory and uni-int decision making, European Journal of Operational Research 207/2 (2010) 848-855

[6] N. Çağman, Contributions to the Theory of Soft Sets, Journal of New Result in Science, 4 (2014) 33-41.

[7] F. Feng, X.Y. Liu, V. Leoreanu-Fotea, Y.B. Jun, Soft sets and soft rough sets, Inform. Sci. 181 (2011), no. 6, 1125-1137.

[8] G. Senel, The parameterization reduction of soft point and its applications with soft matrix, IJCA, accepted.

[9] P.K. Maji, R. Biswas and A.R. Roy, Soft set theory, Computers and Mathematics with Applications 45 (2003) 555-562.

[10] P.K. Maji, A.R. Roy and R. Biswas, An application of soft sets in a decision making problem, Comput. Math. Appl. 44 (2002), 1077-1083.

[11] P. Majumdar and S. K. Samanta, On soft mappings, Comput. Math. Appl. 60 (2010) 2666-2672.

[12] D.A. Molodtsov, Soft set theory-first results, Computers and Mathematics with Applications 37 (1999) 19-31.

[13] S. Mondal and M. Pal, Soft matrices, African Journal of Mathematics and Computer Science Research Vol. 4(13), pp. 379-388, (2011)

[14] T. J. Neog, D.M. Sut, A New Approach to the Theory of Soft Sets, International Journal of Computer Applications 32/2 (2011) 0975-8887.

[15] D. Pei, D. Miao, From soft sets to information systems, in: X. Hu, Q. Liu, A. Skowron, T.Y. Lin, R.R. Yager, B. Zhang (Eds.), Proceedings of Granular Computing, vol. 2, pp. 617621, 2005, IEEE.

[16] N. Cagman, F.Citak, H. Aktas, Soft int-groups and its applications to group theory, Neural Computing and Applications, 21 (Issue 1-Supplement) (2012) 151-158.

[17] M. Shabir, M. Naz, On soft topological spaces, Computers and Mathematics with Applications 60 (2011) 1786 - 1799.

[18] S. Das and S.K. Samanta, Soft Metric Spaces, Annals of Fuzzy Mathematics and Informatics, 6(1) (2013) 77-94.

[19] Y. Xia, L. Zuhua, Some new operations of soft sets, Uncertainty Reasoning and Knowledge Engineering (URKE), 2nd International Conference, pp. 290 - 295, 14-15 Aug. 2012, IEEE.

[20] P. Zhu, Q. Wen, Operations on Soft Sets Revisited, Journal of Applied Mathematics 2013 (2013) 1-7.

[21] I. Zorlutuna, M. Akdağ, W.K. Min, S. Atmaca, Remarks on Soft Topological Spaces, Annals of Fuzzy Mathematics and Informatics, 3 (2) (2012), 171-185. 
Table 1. : Definition of the Soft Points

\begin{tabular}{|l|l|l|}
\hline $\begin{array}{l}\text { In this paper, } \\
\text { Our approach }\end{array}$ & $\begin{array}{l}\text { In [18], } \\
\text { by Sujoy Das et al. }\end{array}$ & $\begin{array}{l}\text { In [21], } \\
\text { by I. Zorlutuna et al. }\end{array}$ \\
\hline $\begin{array}{l}\text { A soft set } \\
f=\{(e, f(e)): e \in E\}\end{array}$ & A soft set & A soft set \\
& $(P, A)=\{(x, P(x)): x \in E\}$ & $(F, A)=\{(e, F(e)): e \in E\}$ \\
where & where & where \\
$e_{i} \in E, e_{j} \in E \backslash\left\{e_{i}\right\}$ & $A \subseteq E, \lambda \in A, \forall \mu \in A \backslash\{\lambda\}$ & $A \subseteq E, e \in A, e^{\prime} \in A \backslash\{e\}$ \\
and & and & and \\
$f\left(e_{i}\right) \neq \emptyset, f\left(e_{j}\right)=\emptyset$ & $P(\lambda)=\{x\}, P(\mu)=\emptyset$ & $F(e) \neq \emptyset, F\left(e^{\prime}\right)=\emptyset$ \\
is denoted by $\left(e_{i_{f}}\right)_{j}$. & is denoted by $P_{\lambda}^{x}$. & is denoted by $e_{F}$. \\
\hline
\end{tabular}

